\title{
Comparative Analysis of Endonasal Lateral Osteotomy and Percutaneous Lateral Osteotomy in Patients with Deviated Nose
}

\author{
Sung-Dong Kim, Ji-Hwan Park, Hyo-Seok Seo, Dong-Joo Lee, Yu-Mi Lee, and Kyu-Sup Cho \\ Department of Otorhinolaryngology-Head and Neck Surgery, Pusan National University Hospital, \\ Pusan National University School of Medicine, Busan, Korea
}

사비 환자에서 비강내 외측절골술과 경피적 외측절골술의 비교 분석

김성동 · 박지환 · 서효석 · 이동주 · 이유미 · 조규섭

부산대학교 의학전문대학원 이비인후과학교실, 부산대학교병원 이비인후과

\author{
Received June 11, 2018 \\ Revised August 16, 2018 \\ Accepted October 23, 2018 \\ Address for correspondence \\ Kyu-Sup Cho, MD \\ Department of Otorhinolaryngology- \\ Head and Neck Surgery, \\ Pusan National University Hospital, \\ Pusan National University \\ School of Medicine, \\ 179 Gudeok-ro, Seo-gu, \\ Busan 49241, Korea \\ Tel $+82-51-240-7824$ \\ Fax $+82-51-246-8668$ \\ E-mail choks@pusan.ac.kr
}

Background and Objectives The purpose of this study was to compare the effectiveness of percutaneous and endonasal lateral osteotomy for the correction of deviated nose.

Subjects and Method Medical records of 60 patients who underwent rhinoplasty to correct deviated nose were reviewed retrospectively. Patients with unilateral osteotomy, revision rhinoplasty, spreader graft, or who had no preoperative or postoperative photos were excluded from the study. The patients were categorized into two groups, which either had C-shaped deviation or I-shaped deviation. Preoperative and postoperative deviation angles were measured and their differences were analyzed according to the approach methods.

Results In the percutaneous approach group, 26 patients had C-shaped deviation and 10 patients had I-shaped deviation, whereas in the endonasal approach group, 17 patients had Cshaped deviation and 7 patients had I-shaped deviation. In the percutaneous approach, the deviation angle was statistically improved in the $\mathrm{C}$-shaped deviation, but in the endonasal approach, it was statistically improved in the C-shaped and I-shaped deviation after surgery. In the $\mathrm{C}$-shaped deviation, the average degrees of improvement of percutaneous and endonasal approach were $5.2^{\circ} \pm 3.6^{\circ}$ and $7.9^{\circ} \pm 5.3^{\circ}$, respectively, which showed significant difference. However, in the I-shaped deviation, the average degrees of improvement of percutaneous and endonasal approach were $2.9^{\circ} \pm 1.3^{\circ}$ and $2.9^{\circ} \pm 1.0^{\circ}$, respectively, with no significant difference. Conclusion The improvement of deviation angle following osteotomy may be different according to the approach methods for deviated nose. Endonasal approach was more suitable than percutaneous approach in the correction of I-shaped deviated nose.

Korean J Otorhinolaryngol-Head Neck Surg 2019;62(3):171-5

Key Words Nose deformities, acquired · Osteotomy · Surgical procedures, operative.

\section{서 론 \\ 사비는 코가 지지구조의 소실 없이 얼굴의 정중앙 수직선}

This is an Open Access article distributed under the terms of the Creative Commons Attribution Non-Commercial License (https://creativecommons.org/licenses/by-nc/4.0) which permits unrestricted non-commercial use, distribution, and reproduction in any medium, provided the original work is properly cited.
으로부터 벗어난 상태를 의미하며, 사비를 교정하는 방법은 여러 가지가 있지만 전위 혹은 변형된 해부학적 구조를 정상 모양으로 재위치 시키는 방법을 주로 이용한다. 연골성 사비 의 교정에는 비중격을 상외측 비연골과 분리시킨 후 일측 혹 은 양측 펼침이식(spreader graft)을 주로 사용한다. 골성 사 비의 교정을 위해서는 절골술(osteotomy)을 시행하여 골부 
피라미드를 정중앙으로 이동시켜야 한다. 절골술은 사비 교 정에 있어 중요한 부분을 차지하며, 일반적으로 휘어진 사비 를 곧게 하거나 비배부가 넓어 좁혀줄 필요가 있을 때, 비혹 제거 후에 생기는 열린지붕변형(open roof deformity)의 교 정을 위해 사용된다. 절골술은 내측절골술과 외측절골술이 있고, 외측절골술의 접근 방법에는 비강내접근법(endonasal continuous technique)과 비강외접근법 모두 가능하며 비강외 접근법에는 경피적접근법(percutaneous perforating technique)과 구강내접근법이 있으나, 주로 비강내접근법과 경피 적접근법이 주로 이용된다. ${ }^{2)}$

일반적으로 심한 사비 또는 비외측벽이 두꺼운 경우는 비 강내접근법이 더 적절하며, 경피적접근법은 비골의 지지부가 안정적으로 유지되고 비점막 손상을 최소화 할 수 있으므로 출혈을 줄여 눈 주위 부종이나 반상 출혈 발생률을 낮출 수 있다고 알려져 있다. 특히 경피적접근법은 골막의 지지를 더 잘 유지할 수 있으므로 2차 코성형술(revision rhinoplasty) 혹 은 외상 후 주위 지지 구조의 보존이 필요한 경우에 유용하게 사용될 수 있다. ${ }^{2)}$ 경피적접근법이 비강내접근법에 비해 술 후 부작용은 줄일 수 있다고 알려져 있지만 사비 교정에 있어 비강내접근법과 비교하여 어느 정도 효과가 있는지에 대해 보고하는 문헌은 많지 않다. 이에 저자들은 비강내접근법과 경피적접근법의 수술 전과 수술 후 사비의 교정 정도를 비교 하여 사비 교정에 있어 외측절골술의 접근 방법에 따른 효과 에 대해 비교 분석을 하고자 하였다.

\section{대상 및 방법}

2009년 1월부터 2017년 2월까지 부산대학교병원에서 코성 형술을 시행 받은 환자에 대하여 후향적으로 분석하였다. 수 술 과정에서 양측 내측 및 외측절골술을 시행한 경우만 포 함하였고, 절골술을 편측만 시행하였거나 최근 비골 골절로 인한 사비, 삽입 물질을 이용한 비배 이식술, 펼침이식, 재수 술, 그리고 수술 전이나 수술 후 사진 기록이 남아있지 않은 경우는 제외하여 최종적으로 총 60 명의 환자에 대하여 분석 하였다. 외측절골술을 경피적접근법으로 시행한 군과 비강 내접근법으로 시행한 군으로 나눈 후 각각의 환자들의 수술 전과 수술 후 사진을 통해 외비의 편위된 각도 변화량을 비 교하였다. 수술 전 사진은 수술 바로 전날 사진을 이용하였 고 술후 사진은 최종 추적 관찰 시 촬영한 사진을 이용하였 다. 경피적접근법을 통한 외측절골술은 $2 \mathrm{~mm}$ 직선형 절골도 (straight osteotome)을 이용하여 양측 비외측의 비부와 안 면부가 만나는 경계부위에 $2 \mathrm{~mm}$ 정도 피부절개를 가하고 비순구(nasolabial fold)를 따라 시행하였다. 비골을 관통하
지 않게 적절한 힘을 주며 이상구를 향해 아래쪽으로 먼저 진 행하였고, 그 뒤에 비배부를 향하여 상방으로 시행하였다. 비 강내접근법을 통한 외측절골술은 먼저 15번 blade로 하비갑 개 상방 기시부에 절개를 가하고 이상구(pyriform aperture) 의 뼈가 확인이 되면 $4 \mathrm{~mm}$ 굴곡형 외측 절골도(curved lateral osteotome)을 이용하여 비순구를 따라 high-low-high 로 시행하였다.

사비에 대한 분류는 Erdem 등 $^{3}$ 의 방식을 이용 하였다. 우 선 환자들의 수술 전과 수술 후의 정면 사진을 기반으로 사 비를 크게 I-형태와 C-형태 2가지 형태로 분류하였다. I-형 태는 사비의 편위가 직선형으로 비배의 골부와 연골부의 경 사가 같은 방향으로 향하면서 중심축을 벗어난 경우로 정의 하였다. I-형태 편위의 각도는 먼저 미간과 윗입술의 중앙을 잇는 수직선을 결정하고, 비근점(nasion)과 비첨을 잇는 선 을 결정한 후 수직선과 이루는 각도를 측정하였다. $\mathrm{C}$-형태는 한 쪽 면은 볼록하고 다른 한 쪽은 오목한 편위로 정의하고 $\mathrm{C}$-형태 편위의 각도는 비근점과 가장 볼록한 지점을 잇는 선과 가장 볼록한 지점과 비첨을 잇는 선 사이의 각도를 측 정하였다(Fig. 1). I-형태의 경우 수술 후 편위각은 $0^{\circ}, \mathrm{C}$-형 태의 경우 수술 후 편위각은 $180^{\circ}$ 에 가깝게 된다.

수술 전과 수술 후의 결과를 평가하기 위해 MB-Ruler Pro (Version 5.0; Markus Bader-MB Software Solutions Iffezheim, Germany)를 이용하여 변수를 측정하였다. 모든 데 이터는 Statistical Package for the Social Science ver. 19.0 (IBM Corp., Armonk, NY, USA)에 입력하여 분석하였고 두 군의 차이를 비교하기 위해 Students' t-test와 Mann-Whitney U-test를 이용하여 유의성을 검증하였고 $p$-value가 0.05 미
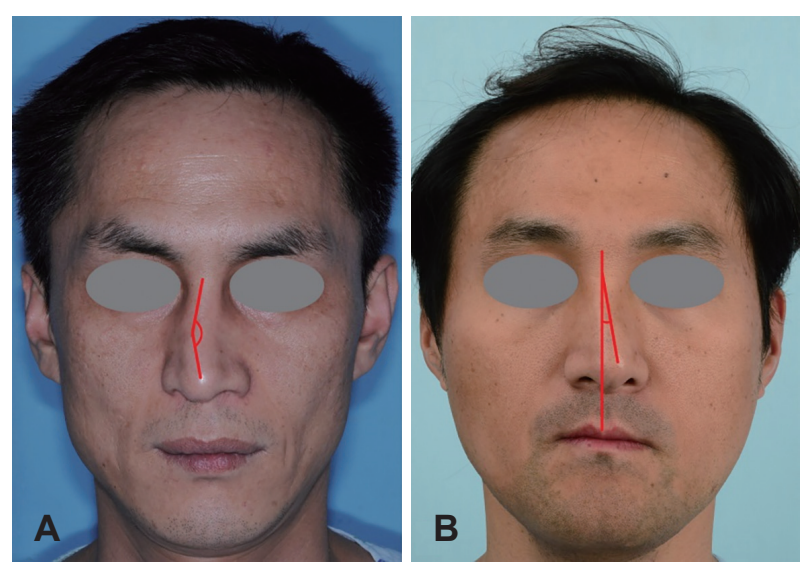

Fig. 1. Measurement of nasal deviation angle. In the C-shaped deviation, the angles were measured between the line along the nasion and the most prominent point of convexity and the line along the most prominent point of convexity and nasal tip (A). In the I-shaped deviation, the angles were measured between the line along the glabella and the midpoint of the upper lip and the line along the nasion and nasal tip (B). 
만일 때 통계적 유의성이 있다고 판단하였다.

\section{결 과}

총 60 명의 환자 중 경피적접근법을 시행 받은 환자는 36 명 이었고 평균 연령은 29.0세였으며 그 중 남성은 29명, 여성은 7명이었다. 경피적접근법을 시행한 군 중 $\mathrm{C}$-형태의 외비 편 위는 26 명(72.2\%), I-형태의 편위는 10 명(27.8\%)에서 확인되

Table 1. Demographic characteristics

\begin{tabular}{lcc}
\hline \multicolumn{1}{c}{ Characteristics } & Percutaneous & Endonasal \\
\hline Age (mean, years) & 29.0 & 29.4 \\
Sex & & \\
$\quad$ Male & 29 & 20 \\
$\quad$ Female & 7 & 4 \\
Type of deviation & & \\
$\quad$ C-shape & 26 & 17 \\
I-shape & 10 & 7 \\
F/U (mean, days) & 98.0 & 92.2
\end{tabular}

F/U: follow-up
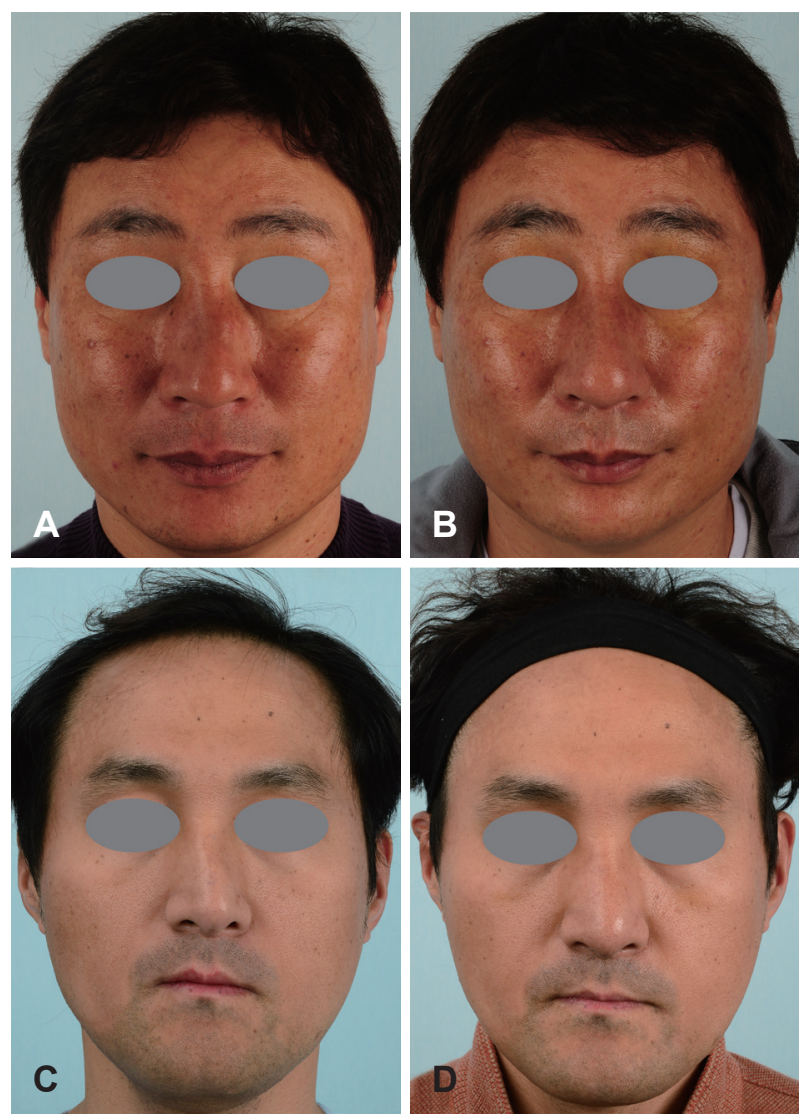

Fig. 2. Postoperative outcomes of deviated nose by percutaneous approach. Preoperative (A and $C$ ) and postoperative (B and D) photos shows a 43-year-old man with $\mathrm{C}$-shaped deviated nose and 41-year-old man with I-shaped deviated nose respectively.
었으며 수술 후 최종 추적관찰 사진 촬영일은 평균 98.0일 (95 196일)이었다. 비강내접근법을 시행 받은 환자는 24명이 었고 평균 연령은 29.4세였으며 그 중 남성은 20명, 여성은 4명 이었다. 비강내접근법을 시행한 군 중 C-형태의 외비 편위는 17 명(70.8\%), I-형태의 편위는 7명(29.2\%)에서 관찰되었고 수 술 후 최종 추적관찰 사진 촬영일은 평균 92.2일(90 168일) 이었다(Table 1).

C-형태와 I-형태 사비 모두에서 경피적접근법과 비강내접 근법을 시행한 군 사이에 수술 전 만곡의 정도는 통계적으로 유의한 차이를 보이지 않았다. 경피적접근법을 시행한 군에 서 $\mathrm{C}$-형태 사비의 경우는 수술 전과 수술 후의 외비 편위각 이 각각 평균 $172.1^{\circ} \pm 3.6^{\circ}, 177.3^{\circ} \pm 1.9^{\circ}$ 였고 통계적으로 유의 한 차이를 보였다 $(p<0.001)$. 하지만 $\mathrm{I}-$ 형태 사비의 경우는 수술 전과 수술 후의 외비 편위각이 각각 평균 $5.9^{\circ} \pm 3.1^{\circ}, 3.0^{\circ}$ $\pm 2.1^{\circ}$ 로 수술 이후 사비가 호전은 되었으나 유의한 차이는 없었다 $(p=0.200)$ (Fig. 2). 비강내접근법을 시행한 군에서는 $\mathrm{C}$-형태 사비의 경우 수술 전과 수술 후의 외비 편위각이 각 각 평균 $169.0^{\circ} \pm 6.2^{\circ}, 176.9^{\circ} \pm 2.1^{\circ}$ 였고 통계적으로 유의한 차
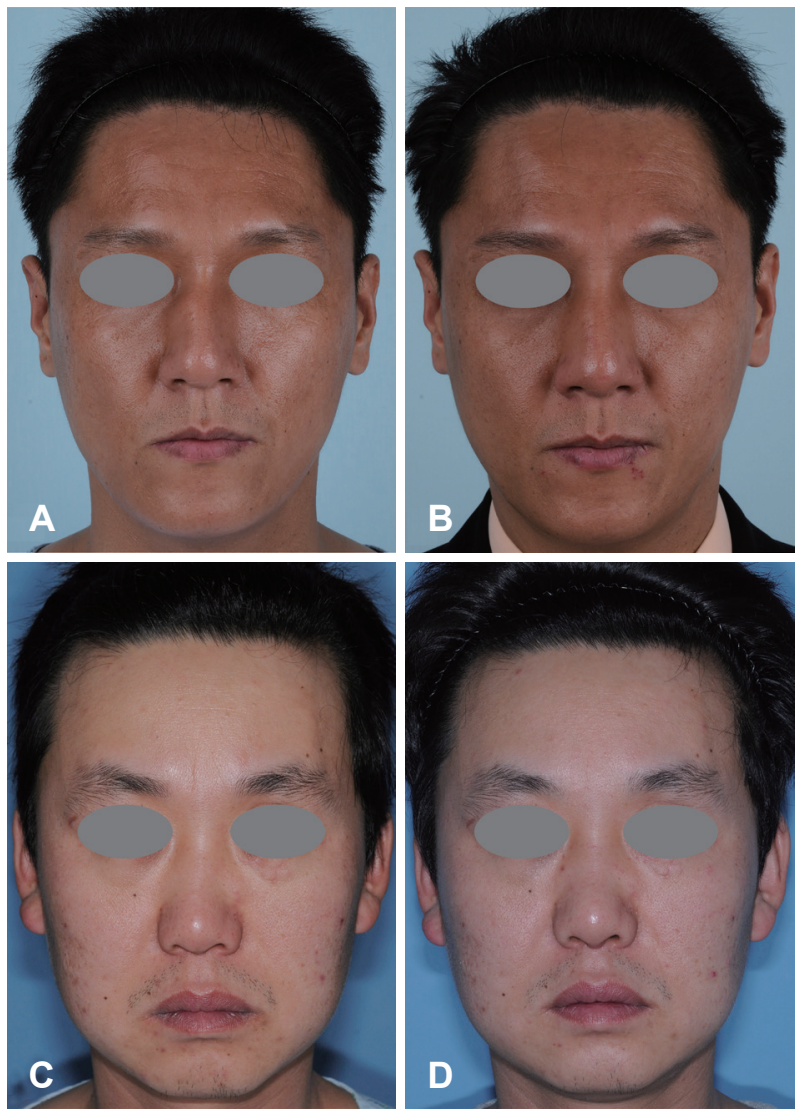

Fig. 3. Postoperative outcomes of deviated nose by endonasal approach. Preoperative (A and $C)$ and postoperative (B and $D)$ photos shows a 36-year-old man with $\mathrm{C}$-shaped deviated nose and 33-year-old man with I-shaped deviated nose respectively. 
Table 2. Preoperative and postoperative deviation angles in the percutaneous and endonasal approach

\begin{tabular}{|c|c|c|c|c|c|c|}
\hline \multirow{2}{*}{ Type } & \multicolumn{3}{|c|}{ Percutaneous approach } & \multicolumn{3}{|c|}{ Endonasal approach } \\
\hline & Pre-op & Post-op & $p$-value & Pre-op & Post-op & $p$-value \\
\hline C-shape & $172.1(3.6)$ & $177.3(1.9)$ & $<0.001$ & $169.0(6.2)$ & $176.9(2.1)$ & $<0.001$ \\
\hline I-shape & $5.9(3.1)$ & $3.0(2.1)$ & 0.200 & $4.2(1.4)$ & $1.3(0.8)$ & 0.008 \\
\hline
\end{tabular}

Data are expressed as the mean (standard deviation) of deviation angle. Pre-op: preoperative, Post-op: postoperative

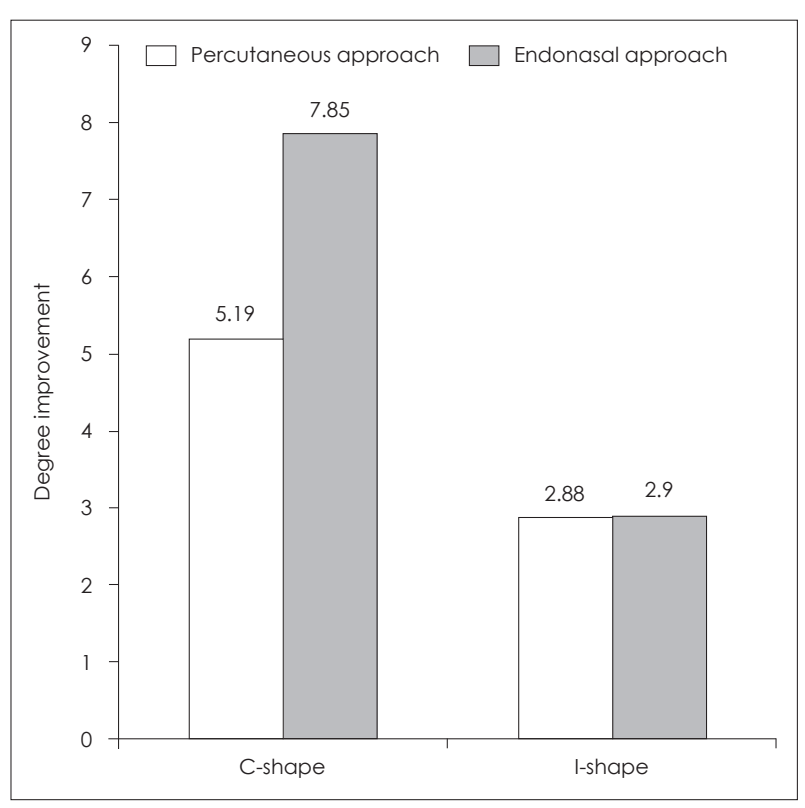

Fig. 4. Degree of improvement between percutaneous and endonasal approach according to the type of deviation. In the Cshaped deviation, the degree of improvement was significantly higher in the endonasal approach $(p=0.036)$. However, the degree on improvement was not different in the I-shaped deviation between the percuataneous and endonasal approach.

이를 보였다 $(p<0.001)$. I-형태 사비의 경우도 수술 전과 수 술 후의 외비 편위각이 각각 평균 $4.2^{\circ} \pm 1.4^{\circ}, 1.3^{\circ} \pm 0.8^{\circ}$ 로 통계 적으로 유의한 차이를 보였다 $(p=0.008)$ (Fig. 3, Table 2).

수술 전과 수술 후의 사비의 형태에 따른 편위각의 차이를 비교하여 보면 C-형태 사비의 경우 경피적접근법에서 평균 $5.2^{\circ} \pm 3.6^{\circ}$ 가 교정되었고, 비강내접근법에서 평균 $7.9^{\circ} \pm 5.3^{\circ}$ 가 교정되어 비강내접근법에서 수술 전 후 편위각 변화량이 더 컸으며 통계학적으로 유의한 차이를 보였다 $(p=0.036)$. 그러 나 I-형태 사비의 경우에서는 경피적접근법과 비강내접근법 에서 각각 평균 $2.9^{\circ} \pm 1.3^{\circ}, 2.9^{\circ} \pm 1.0^{\circ}$ 교정되었고 두 가지 접근 방법에 따른 수술 전 후 편위각 변화량에 있어 통계적으로 유의한 차이는 보이지 않았다( $p=1.000)$ (Fig. 4).

\section{고 찰}

코성형술에서 절골술은 외비 만곡, 특히 골성 비배의 만곡 을 교정하기 위한 필수적인 술식이며, 여러 코성형술과 관련
된 술기들 중 임상에서 사용되는 빈도가 $82.8 \%$ 로 비중격성 형술에 이어 두번째로 흔히 사용되는 술기이다. ${ }^{4)}$ 절골술은 Dufourmentel 등이 비골 측부의 절골 없이 단순히 골부를 내측으로 골절 시키는 방법으로 비혹 제거와 비배부를 좁히 는 술기를 통해 처음 보고하였고, 1906년 Mosher에 의해 외 측 골막하 절골술(lateral subperiosteal osteotomy)이 소개 되었다. ${ }^{5)}$ Webster 등은 1977 년에 현재도 가장 널리 사용되 는 굴곡형 외측 절골도를 이용한 high-low-high 절골술을 보고하여 절골술을 시행하면서도 비강의 안정성을 확보하고 자 하였다. 최근에는 동일한 수술적 결과를 얻으면서도 부작 용을 최소화 할 수 있는 다양한 방법들이 소개되고 있으며 대표적으로 피에조를 이용한 절골술과, lateral chisel을 이용 한 기술도 보고되고 있다. ${ }^{78)}$

절골술은 절골하는 위치에 따라 내측절골술, 외측절골술, 중간절골술로 다양하게 보고되어 왔으며 접근방법에 따라 비강내접근법, 구강내접근법, 경피적접근법 등이 소개 되었 다., ${ }^{1,-11)}$ 각각의 술기에 적합한 적응증은 명확히 확립되어 있지 않은 실정이나 적극적인 절골술을 시행할수록 주변 조직의 손상을 포함한 부작용의 가능성과 빈도도 높아질 수 있으 며, 적절한 골성 비배부의 교정과 함께 이러한 부작용을 최 소화 할 수 있는 방법을 선택하는 것이 중요하다.

비강내접근법을 이용한 외측절골술은 출혈과 술후 부종, 그리고 반상출혈과 같은 합병증의 발생위험이 상대적으로 높다고 알려져 있으며, 경피적접근법을 이용한 외측절골술은 골막의 지지구조를 보존함으로써 비측벽의 붕괴 감소와 함 께 비강 기도의 합병증을 예방하며, 출혈, 반상출혈, 술후 부 종과 같은 술후 합병증도 감소시킨다고 보고하고 있다. ${ }^{2,12}$ 경 피적절골술과 비강내절골술에 따른 비골의 조직학적 상처치 유를 비교한 동물모델에서의 최근 연구에서도 경피적절골술 이 상대적으로 적은 골 손상과 빠른 골치유의 조직학적 소견 을 보인다고 보고하였다. ${ }^{13)}$ 그러나 비강내접근법과 달리 경피 적접근법은 피부의 절개가 필요하며 절골술 후 피부의 반흔 이 남을 수 있고, 특히 피부색이 하얀 여성 환자의 경우 술후 흥터나 착색에 대한 부분이 충분히 고려되어야 한다. ${ }^{1)}$

본 연구에서는 사비의 교정을 위한 외측절골술을 경피적접 근법과 비강내접근법으로 나누어 최종적으로 교정된 수술의 결과를 후향적으로 비교하였다. 일반적으로 교정에 대한 수 
술의 결과는 만곡의 종류에 따라 차이를 보인다고 알려져 있 다. 본 연구에서는 사비를 골부와 연골부가 다른 방향으로 휘 어 있는 $\mathrm{C}$-형태와 골부와 연골부가 같은 방향으로 휘어 있 고, 교정하기 가장 어려운 것으로 알려져 있는 I-형태로 나누 어 분석을 진행하였다. C-형태 사비에서는 경피적접근법과 비강내접근법 모두 수술 전과 비교하여 수술 후 통계적으로 유의한 교정값을 보였으나 I-형태 사비에서는 유의한 교정값 을 보인 비강내접근법과 달리 경피적접근법에서는 술후 교정 값이 통계적으로 유의하지 않았다. $\mathrm{C}$-형태와 $\mathrm{I}$-형태 각각에 서 접근법에 따른 교정값을 비교하였을 때 C-형태 사비에서는 통계적으로 유의한 값을 보여 비강내접근법이 경피적접근법 보다 유의미하게 교정값이 높음을 알 수 있었고, I-형태 사비 에서는 접근법에 따라 통계적으로 유의한 차이를 보이지 않 았다. 이러한 결과는 I-형태 사비의 교정이 C-형태 사비의 교정보다 상대적으로 어렵다는 점을 반영하며, $\mathrm{C}-$ 형태 사비 의 경우 접근법에 따른 교정값의 유의미한 차이는 만곡의 정 도가 심한 환자의 경우 상대적으로 교정값이 커지게 되는데 이러한 환자군에 따른 bias가 영향을 미쳤을 것이라 생각된 다. 그리고 $\mathrm{I}$-형태 사비의 환자가 $\mathrm{C}-$ 형태 사비의 환자에 비해 숫자가 적은 것도 결과에 영향이 있을 것으로 생각된다. C-형 태와 I-형태 사비의 교정에서 비강내접근법이 경피적접근법 에 비해 효과가 좋았던 것은 수술 전 만곡 정도의 차이에 대 한 bias가 완전히 제거되지는 못하였지만 비강내접근법이 경 피적접근법에 비해 골막의 손상을 초래하는 좀 더 적극적인 절골술이라는 것을 의미한다고 할 수 있다.

본 연구는 후향적 분석이어서 환자의 선택이 무작위로 이 루어 지지 못하였고 각군의 환자의 만곡 정도에 따라 결과가 달라질 수 있다는 점, 사비에 대한 분류를 $\mathrm{C}$-형태와 $\mathrm{I}$-형태 에 국한하여 분석을 시행하였던 점, 그리고 I-형태 사비의 환 자가 적은 한계점이 있다. 또한 절골술 후 발생할 수 있는 흔 한 합병증인 술 후 부종과 반상출혈의 정도에 대하여 비교 분석이 이루어 지지 못하여 이에 대한 추가적인 연구가 필요 할 것으로 생각한다. 그러나 연골부 교정이 필요한 환자군을 최대한 배제하고, 절골술만 시행한 환자를 대상으로 두가지 접근법에 따른 절골술의 교정효과를 비교한 연구라는데 의
의가 있다고 할 수 있다.

결론적으로 사비 환자에서 만곡의 형태에 따라 절골술에 따른 교정 효과의 차이가 있음을 알 수 있었다. C-형태 만곡 의 경우는 두 가지 방법이 모두 효과적이지만 I-형태 만곡의 경우는 경피적접근법보다는 비강내접근법으로 절골술을 시 행하는 것이 더 효과적이라고 할 수 있다.

\section{Acknowledgments}

This work was supported by clinical research grant from Pusan National University Hospital in 2019.

\section{REFERENCES}

1) Jang YJ, Oh JK. Rhinoplasty using percutaneous osteotomy. Korean J Otorhinolaryngol-Head Neck Surg 2000;43(9):952-5.

2) Giacomarra V, Russolo M, Arnez ZM, Tirelli G. External osteotomy in rhinoplasty. Laryngoscope 2001;111(3):433-8.

3) Erdem T, Ozturan O. Objective measurement of the deviated nose and a review of surgical techniques for correction. Rhinology 2008; 46(1):56-61.

4) Jin HR, Lee JY, Shin SO, Choi YS, Lee DW. Key maneuvers for successful correction of a deviated nose in Asians. Am J Rhinol 2006; 20(6):609-14.

5) Dnecke HJ, Meyer R. Plastic surgery of head and neck: corrective and reconstructive rhinoplasty. New York: Springler-Verlag NY Inc; 1967. p.48-67.

6) Webster RC, Davidson TM, Smith RC. Curved lateral osteotomy for airway protection in rhinoplasty. Arch Otolaryngol 1977;103(8): 454-8.

7) Tirelli G, Tofanelli M, Bullo F, Bianchi M, Robiony M. External osteotomy in rhinoplasty: Piezosurgery vs osteotome. Am J Otolaryngol 2015;36(5):666-71.

8) Çakr B, Finocchi V, Tambasco D, Öreroğlu AR, Doğan T. Osteoectomy in rhinoplasty: A new concept in nasal bones repositioning. Ann Plast Surg 2016;76(6):622-8.

9) Hilger JA. The internal lateral osteotomy in rhinoplasty. Arch Otolaryngol 1968;88(2):211-2.

10) Goldfarb M, Gallups JM, Gerwin JM. Perforating osteotomies in rhinoplasty. Arch Otolaryngol Head Neck Surg 1993;119(6):624-7.

11) Parsa FD. Intraoral versus intranasal approach to lateral osteotomy. Plast Reconstr Surg 1992;90(2):341.

12) Diamond HP. Rhinoplasty technique. Surg Clin North Am 1971; 51(2):317-31.

13) Öğreden Ş, Rüzgar S, Tansuker HD, Taşkın Ü, Alimoğlu Y, Aydın S, et al. Histopathological comparison of bone healing effecs of endonasal and percutaneous lateral osteotomy methos in rabbit rhinoplasty model. Braz J Otorhinolaryngol 2018;84(5):540-4. 